\title{
Learning Communities: Factors Influencing Faculty Involvement
}

\author{
Patricia A. Lapoint \\ McMurry University
}

The debate in higher education has inspired broad discussion about the quality of undergraduate education. Several of these criticisms have focused on a lack of curricular coherency, an emphasis on research versus teaching, and intellectual isolationism within the academic community. The debate has inspired broad discussion and questions the overall quality of undergraduate education in this country. One attempt by some institutions of higher education to counter these criticisms is through the development of various curricular structures referred to as learning communities. Learning communities represent a structural response to curricular fragmentation by promoting curricular coherence, intellectual and social community, and sense of common purpose within the academic environment. The research on learning communities as been limited in identifying factors which prompt faculty to become involved in this kind of teaching and learning structure. The purpose of this research study is to provide additional insights on variables that influence faculty involvement in learning communities. Three variable sets-faculty background, structural, and organization/environmental-frame the theoretical basis for the research study.

Keywords: learning communities, quality management, curricular innovation

\section{INTRODUCTION}

The debate in higher education over the past several decades has centered around the academic curriculum and the teaching and learning process. Several of these criticisms have focused on a lack of curricular coherency, an emphasis on research versus teaching, and intellectual isolationism within the academic community. The debate has inspired broad discussion and questions the overall quality of undergraduate education in this country. One attempt by some institutions of higher education in the United States to counter these criticisms has been through the development of various curricular structures referred to as learning communities. Learning communities represent a structural response to curricular fragmentation by promoting curricular coherence, intellectual and social community, and sense of common purpose within the academic environment. Jean M. Henscheid estimates the number of learning communities currently in existence in the United States ranges from approximately 250 to greater than 1,000; the higher end of the range is for the 2-year community colleges (Henscheid, 2015).

The research on learning communities as been limited in identifying factors which prompt faculty to become involved in this kind of teaching and learning structure. Therefore, the purpose of this research study is to provide additional insights on selected variables that influence faculty involvement in learning communities. Three variable sets - faculty background, structural, and organization/environmental — frame the theoretical basis for the research study. 
Learning communities offer an opportunity for institutions of higher education to structure the teaching and learning environment in such a way as to improve the quality of the learning outcomes. The research literature focuses mainly on student learning outcomes enhance by the learning community model. Little research focuses on the faculty side of the teaching and learning process in learning communities. Traditionally, faculty prefer to teach in independent, autonomous environments and where students learn in silos. Analysis of the data suggests that the independent variables Academic Planning, Professionalism in Academic Setting, and Selection/ Evaluation/ Reward account for 57.7 percent of the variance in the dependent variable, faculty involvement.

The most significant implication of this research for practitioners is that the independent variables Academic Planning, Professionalism in Academic Setting, and Selection/Evaluation/ Reward are generally recognized as important climate variables for faculty involvement in learning communities. Consequently, it falls upon administrative leadership to develop and nurture a conducive academic climate in which faculty may develop a more collaborative and innovative teaching and learning atmosphere.

The purpose of this study is to determine the strength of the relationships amongst selected variables within the three dominant variable sets - faculty background, structural, and organizational characteristics and the extent of the contribution these variables make to an explanation of faculty involvement in learning communities. To accomplish the goal of the study, the following research questions guide the inquiry.

\section{Research Questions}

R1: Which independent variables have the strongest relationship to the involvement of faculty in learning communities.

R2: To what extent do these variables contribute to the explanation of faculty involvement in learning communities.

\section{LITERATURE REVIEW}

A search of the literature is conducted on the relevant topics related to this research study on learning communities. Various resources such as periodicals, bibliographic indices, bibliographic computerized data bases, and published bibliographies provide the depth, breadth, and currency of knowledge essential to lay the appropriate foundation for this study. As source guides to the literature, Resources in Education and Current Index to Journals in Education -now accessible as the two ERIC (Educational Resources Information Center) data bases-, Higher Education Abstracts, Education Index, Psychological Abstracts, Dissertation Abstracts International, and the Integrated Postsecondary Education System (IPEDS) represent the vast majority of potential reference materials to begin the review of the literature on learning communities and related material.

A second important source on learning communities comes from the Washington Center for Improving the Quality of Undergraduate Education in Olympia, Washington. Several conversations between me and Jean MacGregor, Associate Director of the Washington Center, led to other material in both written and verbal formats. Extensive discussions related to learning communities with Dr. Vincent Tinto (Syracuse University), Dean Roberta Matthews (LaGuardia Community College), and Dr. Kelly Lynch (Babson College) were rich in practical and substantive detail on learning community experiences. As a result of the entire search process, what follows is the summation of that effort.

\section{Faculty Outcomes}

Barbara Leigh Smith's research reveals that students are not the only beneficiaries of the learning community structure. "Faculty members find teaching in learning communities rich and revitalizing...It puts them in touch with their colleagues in a creative endeavor and allows them to invest deeply in their students" (Smith 1991, p. 45). Faculty collegiality and job enrichment have been found to be the most important benefits accruing to faculty who have experienced teaching in the learning community structure. 
A large majority of faculty surveyed found the learning community environments interesting, challenging, and enjoyable. Many faculty in higher education agree that the most important factor in successfully linking courses is the relationship of the faculty team. At the same time, instructors feel that the ability to demonstrate multiple and even conflicting viewpoints about course material can be enriching, both for faculty and students- (Skagit Valley College 1992; Hubbard 2004).

Faculty issues in the learning community literature have generally been limited to studies of faculty perceptions of teaching in the learning community structure and faculty development (Smith 1988; Gabelnick et al. 1990; Finley 1991; Tollefson 1991; Skagit Valley College 1992; Matthews 1994). Gary Tollefson's dissertation research focuses on community college faculty in the state of Washington who have taught the learning community structure. The research attempts to identify faculty perceptions regarding the impact learning communities have on general education programs, on the learning community implementation process on their relationship to positive student efforts, and on their effect on faculty development. Tollefson's research reveals that “...faculty members who have initiated, planned, and taught in collaborative learning communities feel empowered by their experience. They [sic faculty] indicated that teaching in a learning community was invigorating, that the teaching environment was improved, and that they felt rewarded by their association with learning communities" (Tollefson 1990, p. 10). In that same research study (Tollefson 1990), faculty members indicated that learning communities create a greater sense of community than conventional classes. The pedagogical style characteristic of the learning and the organizational framework that is student-centered rather than professor-centered emphasizes active student and faculty interactions and involvement. Tollefson concludes that the learning community structures have a significant influence in energizing and empowering both faculty and students. Similarly, the curriculum coalesces around fresh and exciting activities in an improved teaching and learning environment.

\section{Academic Discipline}

Different types of learning community structures tend to attract faculty from different discipline/scholarly orientations. For example, "...faculty in the sciences seem especially attracted to clusters, linked courses, and the federal learning community model. ... The more integrated coordinated study learning community model. ... The more integrated coordinated study learning community model seems especially attractive to faculty in the humanities and the social sciences..." (Gabelnick et al. 1990, p. 78):

\section{LEARNING COMMUNITIES AND GENDER}

The feminist literature supports the notion that cooperation, shared power, development of a personal connection to the material studied and an emphasis on affective learning are important features consistent with the learning community concept, Belenky, Clinchy, Goldberger, and Tarule that "... women are particularly attracted to connected knowing" (Belenky et al, 1986, p. 35). As such, women tend to be highly visible in the learning community effort on numerous campuses around the country.

In a study by Martin Graff which examined the effects of gender on the sense of the learning community environment, the author found few insignificant differences between female and male students (Graff, 2003). Confirming the findings of Graff, Deborah Schussler found similar results of male and female student perceptions of their academic performance, relationships, and sense of belonging in residential learning communities (Schussler, 2008).

\section{CAREER STAGE AND LEARNING COMMUNITIES}

The learning community literature suggests that career stage is a strong factor in faculty involvement in learning communities. "Learning communities have been particularly attractive to mid-career faculty members. The tedium that comes from assuming the same old roles and teaching the same old courses is an important and neglected issue at many institutions" (Smith 1991, p. 46). Learning communities tend to provide a catalyst for innovative teaching and offer new challenges to those faculty in their mid-to-late 
career stages. The reason that learning communities are effective in rekindling this spirit is because faculty become learners again. Faculty become empowered to recreate the curriculum in an atmosphere of mutual trust, respect, and responsibility rather than through the political negotiation process of the curriculum committee.

To position this research study properly within the context of the research literature, an understanding of the appropriate theoretical framework underpinning faculty involvement in learning communities is also important. There are three major sets of variables that directly and indirectly influence faculty involvement in learning communities-Structural Characteristics, Faculty Background Characteristics, and Organizational/Environmental Characteristics. Figure 1 reflects the conceptual framework for faculty involvement in learning communities (see Figure 1).

\section{FIGURE 1 \\ CONCEPTUAL FRAMEWORK OF FACULTY INVOLVEMENT IN LEARNING COMMUNITIES}

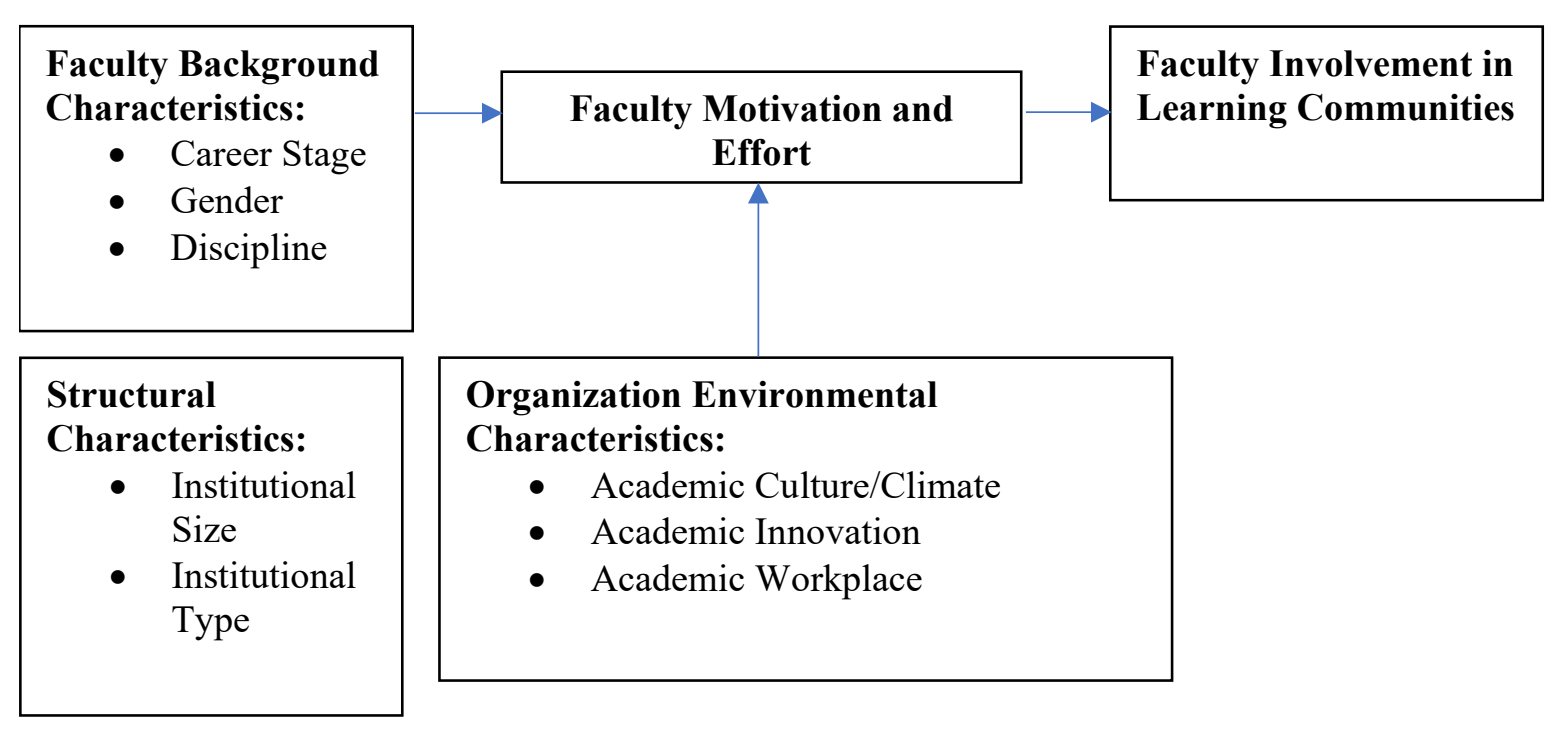

\section{STRUCTURAL CHARACTERISTICS}

Structural characteristics are defined as those aspects of the organization that provide a supporting framework for the essential parts of a complex whole. Although there are numerous structural characteristics potentially available for discussion, the research literature on learning communities highlights two of them in particular-institutional size and institutional type. Therefore, for the explicit purposes of this research study, institutional size and institutional type represent the two primary variables in the structural characteristics variable set.

\section{Institutional Size}

The research literature is replete with studies on the impact that institutional size has on student outcomes. Institutional size by itself has very little effect on student outcomes. It is suggested that institutional size an indirect influence on student outcomes mediated through the interpersonal relationship between the student and the professor. Consistent with a substantial body of evidence is the fact that in large institutional settings (or large public institutions) there is, generally, an inhibiting influence as a function of size on different dimensions of social and academic involvement during college (Pascarella 1984; Stoecker and Pascarella 1988; Stoecker, Pascarella and Wolfle 1988; Smart 1986: Ethington and Smart 1986). 
This body of evidence supports the notion that large institutions of higher education tend to have a negative influence on a student's level of social involvement and interaction with faculty. Therefore, the size of the higher education institution may be an important variable affecting the professor's willingness and, perhaps, opportunity to interact with students as well as with other faculty colleagues; both willingness and opportunity are desirable components in the learning community structures. The inherent nature of the contact amongst faculty and students in the learning communities demands that a close, interpersonal relationship, and a facility to exchange across the disciplinary, structural boundaries be present. Suggestions are made in the learning community literature that the institutional size variable is an insignificant factor with respect to various learning community outcomes. The descriptive qualitative research in which many of these suggestions are made necessitate a closer look at the issue of institutional size.

\section{Institutional Type}

For the purposes of this research study, institutional type is defined according to the Carnegie Classification scheme developed by the Carnegie Foundation for the Advancement of Teaching. Accredited institutions of higher education are grouped into categories based largely on their academic missions. These categories are: Research Universities I \& II, Doctoral-Granting Universities I \& II, Masters Colleges and Universities I \& II, Baccalaureate Colleges I \& II, Associates of Arts Colleges, and Professional Schools and Specialized. The research on institutional type tends to be less clear in its findings on student outcomes than institutional size. The following typifies several areas of the research literature where institutional type may, however, have an impact on outcomes. There appears to be moderate evidence to support the notion that liberal arts colleges are more positively predisposed to the value attached to acquiring a liberal education, although the magnitude of the effect is sufficiently complex, thus preventing adequate estimate of the effect size (Pace 1974; 1984).

\section{Faculty Background Characteristics}

The learning community concept provides faculty with the opportunity to reframe the work environment, to become empowered to shape their work and to engage in meaningful and significant work. The autonomy to restructure pedagogy enriches not only the curriculum, but also provides invaluable faculty development (Gabelnick, 1990). Research findings highlight the importance and significance of matching the individual and the job and the strength of the environmental influences on faculty motivation. Congruent and strong internal environments frequently lead to positive organizational outcomes, among which may include a higher level of faculty involvement in learning communities.

\section{METHODOLOGY}

Data for this study was collected from faculty representing all types of institutions of higher education in the United States. The target population for this study represents faculty who teach at institutions of higher education in the United States that have implemented some form of learning community such as linked courses, learning clusters, freshman interest groups, federated learning communities and coordinated studies. Tables 1 and 2 identify the gender and institutional breakdown of the target population versus the respondent group (see Table 1 for gender and Table 2 for institutional type).

\section{TABLE 1 \\ GENDER FREQUENCIES AND PERCENTAGES FOR TARGET POPULATION AND RESPONDENT GROUP}

\begin{tabular}{|cc|cc|}
\hline \multicolumn{2}{|c|}{ TARGET POPULATION } & \multicolumn{2}{c|}{ RESPONDENT GROUP } \\
\hline Men & Women & Men & Women \\
\hline 762 & 456 & 343 & 284 \\
\hline $63.0 \%$ & $37.0 \%$ & $54.7 \%$ & $45.3 \%$ \\
\hline
\end{tabular}


TABLE 2

\section{COMPARISON OF THE TARGET POPULATION VERSUS THE RESPONDENT GROUP BY} INSTITUTIONAL TYPE

\begin{tabular}{|l|c|c|}
\hline INSTITUTION TYPE & TARGET POPULATION & RESPONDENT GROUP \\
\hline Research Universities & $218(17.9 \%)$ & $104(16.6 \%)$ \\
\hline Doctoral-Granting Universities & $70(5.7 \%)$ & $33(5.3 \%)$ \\
\hline Master's Universities and Colleges & $165(13.6 \%)$ & $91(14.5 \%)$ \\
\hline Baccalaureate Colleges & $306(25.1 \%)$ & $81(12.9 \%)$ \\
\hline Specialized and Professional Schools & $21(1.7 \%)$ & $13(2.1 \%)$ \\
\hline 2-year Colleges & $438(36.0 \%)$ & $305(48.6 \%)$ \\
\hline
\end{tabular}

Two lists, one for institutions and one for faculty in the United States, that are currently or have been previously engaged in a learning community come from two primary sources, the Washington Center for Improving the Quality of Undergraduate Education at The Evergreen State College and The National Center on Postsecondary Teaching, Learning and Assessment at Pennsylvania State University. Development of the institutional and faculty lists occurred in two stages. Stage one involved acquiring information on higher education institutions involved in learning communities from the previously mentioned sources. Eightyfive colleges and universities were originally identified. Telephone contacts to each of these institutions were made to determine if they were directly involved in a learning community structure and to solicit their participation in this research study. Thirty-four institutions were deleted from the institutional list because of either not having one of the structural forms of the learning community or not desiring to participate in the research study. As a result of the initial contacts, seven colleges and universities were added to the institutional list as referrals bringing the total institutional participation to fifty-eight colleges and universities. During stage two, requests were made for the names of faculty who teach in the learning community structure at their respective institutions. The majority of the fifty-eight colleges and universities submitted the names of faculty; however, several institutions preferred that the survey instruments be sent to an institutional coordinator for distribution.

\section{Instrumentation}

The data were collected by a questionnaire--the Organizational Climate for Teaching and Learning (OCS) developed by the National Center for Research to Improve Postsecondary Teaching and Learning at the University of Michigan. The primary purposes of the Organizational Climate for Teaching and Learning survey are to provide a quantitative assessment of several broad dimensions of an institution's academic culture, to assess the organizational and administrative climate for teaching and learning, and to obtain a measure of faculty motivation for and involvement in teaching and learning. The Personal Data Section of the OCS instrument was modified accordingly to reflect the unique demographic questions required for this research study.

The scales on the Organizational Climate Survey instrument vary. Section I scales require the respondent to distribute one hundred points for each item. Peterson and White contend that a one- - hundredpoint distribution across items in a specific index provides a better method of discrimination of personal values and beliefs than would be possible with a Likert-scaled item (Peterson and White, 1992). Sections I-VI 11 are numerically scaled as I (no emphasis) to 5 (very strong emphasis). Section IX (Personal Data) requires the respondent to fill in the appropriate personal and demographic information.

\section{Distribution and Collection of Data}

The survey instrument was distributed to the subjects in four waves of mailings - wave one, 616; wave two, 263; wave three, 227; and wave four, 112 questionnaires respectively for a grand total of 1,218 . The response rates for the four mailings are 135 (228), 53 (208), 45 (208) and 24 (21\%) respectively. Due to the initial inadequate response rate, a first follow - up contact was necessary. Non-respondents were mailed a 
postcard as a reminder to return the questionnaire. For those institutions not submitting names of faculty, a telephone call was placed to the contact coordinator for the follow up reminder. As a result of this second effort, an additional 315 questionnaires were returned representing a cumulative total of 572 (47\%) responses. The second follow up yielded an additional 109 responses for a grand total of 681 (568) returned questionnaires. Of the 681 returned questionnaires only 627 were usable for an overall response rate of 51.5 percent.

\section{Selection of Variable}

A stepwise regression process was applied to the initial set of variables (36 in total) to eliminate those variables not statistically significant to this study. The statistically significant independent variables that remained are Academic Planning (AP), Challenge of Academic Work (CAW), General/ Liberal Education (GLE) Individual Thinking Skills (ITS) Innovation (INN), Professionalism in Academic Setting (PAS), Resource Availability (RÄ), Resists (RES), Selection/ Evaluation/ Reward (SER), and Student Outcomes Assessment (SOA). The dependent variable is faculty involvement (FI).

\section{Scoring of the Data}

The scoring procedure for the initial set of variables as represented by the survey instrument is as follows. Four sets of blocks each containing the variables Teamwork, Innovation, Rational, and Market have a zero to 100-point value range for each variable within each block; each separate block sums to one hundred points. Block Two contains the variables General Improvement of Society, Contribute Productively to Society, General/ Liberal Education, Individual Values Clarification, and Individual Thinking Skills, with one hundred points distributed over the five variables. Block Three contains the variables Collegial, Formal/ Rational, Autonomous, Anarchic, and Political. Block Four contains the variables Leads, Adapts, Responds, and Resists. Both Block Three and Block Four have a zero to 100-point value range with each block sunning to one hundred points. The variables Academic Innovation, Professionalism in Academic Setting, Challenge of Academic Work, Educational Missions/ Goals, Academic Planning, Governance, Resource Allocation, Communication/ Information, Academic/ Curricular/Program Management, Faculty/ Instruction Development, Selection/Evaluation/Reward, Student Outcomes Assessment, Satisfaction, Commitment Academic Administrative Support, Resource Availability, and Faculty Involvement have several items, each of which has a scale value from one to five. Within each of these variables, the item values are summed and averaged. The initial stepwise regression produced the results as shown in Table 3 (see Table 3 ).

TABLE 3

\section{RESULTS OF THE INITIAL STEPWISE MULTIPLE REGRESSION}

\begin{tabular}{|l|l|}
\hline MULTIPLE R & .81313 \\
\hline R SQUARE & .66118 \\
\hline ADJUSTED R SQUARE & .65567 \\
\hline STANDARD ERROR & .46226 \\
\hline
\end{tabular}

The specific contribution of variables to the R Square are identified in Table 4 . 
TABLE 4

CONTRIBUTION OF VARIABLES TO THE R SQUARE

\begin{tabular}{|l|l|}
\hline VARIABLE & R SQUARE \\
\hline Selection/Evaluation/Reward & .498 \\
\hline Academic Planning & .069 \\
\hline Student Outcomes Assessment & .035 \\
\hline Challenge of Academic Work & .023 \\
\hline Resource Availability & .010 \\
\hline General/Liberal Education & .010 \\
\hline Individual Thinking Skills & .005 \\
\hline Professionalism- Academic Setting & .004 \\
\hline Resists & .004 \\
\hline Innovation & .002 \\
\hline TOTAL & .660 \\
\hline
\end{tabular}

Approximately 66.0 percent of the variation in faculty involvement can be attributed to the variation in the combination of the values of Academic Planning, Challenge of Academic Work, General/ Liberal Education, Individual Thinking Skills, Innovation, Professionalism in Academic Setting, Resource Availability, Resists, Selection/ Evaluation/ Reward and Student Outcomes Assessment (see Table 4).

\section{Effects of Multicollinearity}

Multicollinearity may be problematic when two or more independent variables in the regression equation are highly correlated. A cursory examination of the pairwise correlation coefficients between each pair of the ten independent variables in the equation from the initial stepwise regression was used to detect multicollinearity. Table 5 shows the correlation coefficients for each of the independent variables in the initial regression equation (see Table 5).

TABLE 5

\section{CORRELATION COMPARISONS FOR HIGHLY MULTICOLLINEAR INDEPENDENT VARIABLES}

\begin{tabular}{|l|l|l|l|}
\hline INDEPENDENT VARIABLES & $\begin{array}{l}\text { PAIRWISE } \\
\text { CORRELATIONS }\end{array}$ & \multicolumn{2}{l|}{$\begin{array}{l}\text { CORRELATIONS/ } \\
\text { FACULTY INVOLVEMENT }\end{array}$} \\
\hline $\begin{array}{l}\text { Individual-Thinking Skills/Challenge } \\
\text { Academic Work }\end{array}$ & .1975 & .1884 & .6235 \\
\hline Innovation/Challenge- Academic Work & .2350 & .1778 & .6235 \\
\hline $\begin{array}{l}\text { Professionalism in Academic } \\
\text { Setting/Challenge Academic Work }\end{array}$ & .5739 & .5296 & .6235 \\
\hline Resists/Challenge Academic Work & -.2270 & -.1334 & .6235 \\
\hline $\begin{array}{l}\text { Selection/Evaluation/Reward and } \\
\text { Challenge of Academic Work }\end{array}$ & .6247 & .7071 & .6235 \\
\hline $\begin{array}{l}\text { Professionalism in Academic } \\
\text { Setting/Innovation }\end{array}$ & .2225 & .5296 & .1778 \\
\hline Resource Availability/Innovation & .2651 & .5780 & .1778 \\
\hline Resists/Innovation & -.1574 & -.1334 & .1778 \\
\hline $\begin{array}{l}\text { Selection/Evaluation/Reward and } \\
\text { Innovation }\end{array}$ & .1947 & .7071 & .1778 \\
\hline $\begin{array}{l}\text { Resists/Professionalism Academic } \\
\text { Setting }\end{array}$ & .2034 & -.1334 & .5296 \\
\hline
\end{tabular}




\begin{tabular}{|l|l|l|l|}
\hline Resists/Resource Availability & -.1973 & -.1334 & .5780 \\
\hline Selection/Evaluation/Reward and Resists & -.1778 & .7071 & -.1334 \\
\hline Student-Outcomes Assessment/Resists & -.1486 & .5891 & -.1334 \\
\hline
\end{tabular}

Based of the pairwise correlations between the independent variables, seven variables (Challenge of Academic Work, General/Liberal Education, Individual Thinking Skills, Innovation, Resource Availability, Resists, Student Outcomes Assessment) are highly intercorrelated with one another. As a result, a second stepwise regression is performed on the three independent variables remaining (Academic Planning, Professionalism in Academic Setting, Selection/ Evaluation/Reward). The results of the second regression are presented in Table 6 (see Table 6).

TABLE 6

RESULTS OF SECOND STEPWISE MULTIPLE REGRESSION

\begin{tabular}{|l|l|}
\hline MULTIPLE R & .77724 \\
\hline R SQUARE & .60310 \\
\hline ADJUSTED R SQUARE & .60155 \\
\hline STANDARD ERROR & .49818 \\
\hline
\end{tabular}

For each of the variables in the second regression equation, the explained variance (R Square) accounted for in the dependent variable, faculty involvement, is approximately 60.3 percent (see Table 6). Table 7 identifies the specific contribution to the R Square of the four independent variables to the dependent variable faculty involvement (see Table 7).

TABLE 7

\section{CONTRIBUTION OF THE VARIABLES TO THE R SQUARE FOR THE SECOND REGRESSION EQUATION}

\begin{tabular}{|l|c|}
\hline VARIABLE & R SQUARE \\
\hline Selection/Evaluation/Reward & .500 \\
\hline Academic Planning & .068 \\
\hline Challenge of Academic Work & .026 \\
\hline Professionalism in Academic Setting & .009 \\
\hline TOTAL & .603 \\
\hline
\end{tabular}

The findings of the multiple regression analysis to determine the extent of influence of variables on faculty involvement in learning communities suggest that ten variables identified in this study have the strongest significant relationship to and explanation of faculty involvement in a learning community, and account for approximately a 66.0 percent explanation of the variance in faculty involvement (see Table 4). However, after factoring in the effects of multicollinearity, only the variables Academic Planning, Challenge of Academic Work, Professionalism in Academic Setting and Selection/ Evaluation/ Reward are significant, and account for approximately 60.3 percent of the variance in faculty involvement. Each of these variables is part of the larger organizational/ environmental variable set and this may infer that the organizational/ environmental set and subsets are more important to the explanation of faculty involvement in learning communities than either the structural or faculty background sets. This conclusion is consistent with much of the body of literature on the impact of contextual variables on various outcomes in different organizational settings. The cultures and subcultures of academic organizations have been historically characterized as individualistic and competitive, reinforced by highly segmented departmental organizational structures Implicit values within these departmental frameworks shape the beliefs, attitudes, and behavior of organizational members. The qualities often associated with individualism and 
competitiveness create obstacles to curricular reform, thereby inhibiting a more collaborative approach to the teaching and learning process.

Furthermore, Academic Planning, Professionalism in Academic Setting and Selection/ Evaluation/Reward are generally categorized as climate variables as opposed to culture variables. This distinction between culture and climate provides us with a more focused and delineated perspective of organizational members ${ }^{t}$ perceptions, motivational forces and malleability. Organizational climate reflects more a psychological foundation, and individual-level focus, as opposed to the enduring and holistic approach of culture. As such, these climate variables can be more easily managed and manipulated to serve both individual and organizational purposes.

Faculty that are recruited to teach in learning community structures based upon their competence and commitment to teaching and learning, and promotion, evaluation and reward systems based upon teaching performance account for approximately 50.0 percent of the explained variance in faculty involvement in learning communities. In contrast to much of the previous research on academic selection, evaluation and reward systems, the variable Selection/ Evaluation/ Reward has a much greater impact on the dependent variable in this study. Based upon the findings from this study, it can be inferred that faculty who teach in a learning community highly value the recognition and rewards of teaching as both intrinsic and extrinsic catalysts in their decision to become involved in the learning community at their respective institutions. Consequently, rewards play an extremely important role in the recruitment and maintenance of faculty to teach in the learning community.

\section{CONCLUSIONS}

Conclusions for research questions one and two: Which independent variables have the strongest relationship to the involvement of faculty in learning communities and to what extent do these variables contribute to the explanation of faculty involvement in learning communities? Based upon the findings of this study, 10 variables have the strongest significant relationship to and explanation for faculty involvement in learning communities. The 10 variables account for 66.0 percent of the explained variance in faculty involvement (see Table 4). Taking into consideration the multicollinearity effect and the assumptions of multiple regression, the variance is 60.3 percent explained by the remaining variables Academic Planning, Challenge of Academic Work, Professionalism in Academic Setting, and Selection/ Evaluation/ Reward (see Table 7). Each of these variables are part of the Organizational/Environmental set of the conceptual framework (see Figure 1). This conclusion is consistent with much of the body of literature on the impact of contextual variables on various outcomes in different organizational settings. Implicit values in the academic environment shape the beliefs, attitudes, and behaviors of organizational members in both overt and covert ways. Strong organizational cultures/climates are a prerequisite for faculty to become highly involved in teaching in a learning community.

Furthermore, the variable Selection/Evaluation/Reward has a much greater impact on the dependent variable in this study. This finding suggests that faculty who teach in a learning community highly value the recognition and the rewards of teaching as both intrinsic and extrinsic catalysts for their involvement. Consequently, rewards play a significant role in the recruitment and maintenance of faculty to teach in the learning community.

\section{Limitations and Future Research}

Although an attempt has been made to identify as many institutions currently engaged in a recognized form of learning community, it is highly likely that some institutions are missed. At present, there does not exist a complete and comprehensive list of all such institutions that have implemented some recognized form of a learning community. In addition, the variables chosen for this study are self-selected from the literature on learning communities and are by no means intended to portray all possible variables that may have an influence on faculty involvement in learning communities. Each variable has been assigned to groupings (variable sets) within a conceptual framework of faculty involvement. 
The findings from this research study offer other possible avenues of future research inquiry. The arbitrary setting of screening criteria used in the stepwise multiple regression procedure, removed the possibility of a closer examination of other variables not in the initial regression equation. Consequently, the variables Teamwork, Career Stage, Collegial, Communication/ Information, Satisfaction and Commitment commonly associated with learning communities, and which one might have expected to remain in the regression, may require further exploration. The findings on the variable Teamwork are especially puzzling in this study. As a crucial element in collaborative teaching and learning systems, teamwork represents a most fundamental and basic value for faculty involvement in learning communities. Perhaps, faculty perceptions of teamwork as operationally defined in this study is negatively skewed in connection to academic administrators in general. As if often the case, faculty generally do not immediately describe their relationship to administrators in terms of teamwork, but rather often perceive that relationship as adversarial in nature. more refined examination of the variable Teamwork is clearly warranted. A possible replication study in which the variable Teamwork is more precisely and contextually operationalized with higher content validity may reduce some of the confusion on this variable's contribution to the explanation of faculty involvement in learning communities. In addition, as a combination variable, Selection/ Evaluation/ Reward could be separated into three distinct variables; the purpose of which is to explore the relative impact each has on faculty involvement in learning communities. A more directed research effort may prove to be a valuable and insightful line of inquiry for practitioners in both the foundation - building activities and on-going administration of their learning communities.

Finally, this research study may provide a springboard for various multiple cross-tabulation analyses. The variables Gender, Institutional Type, Institutional Size, Academic Discipline, Career Stage and Type of Learning Community Structure have the potential for furthering our understanding of unique learning community differences.

In summation, learning communities hold much promise for improving the quality of undergraduate education in the future. Although it is hoped that this research study contributes in some way to the body of knowledge on learning communities, much is still to learn. More specifically focused research efforts on learning communities are clearly indicated and may yield conceptual as well as practical information to future researchers in both basic and applied research activities.

\section{REFERENCES}

Beach, A.L., \& Cox, M.D. (2009). The Impact of Faculty Learning Communities on Teaching and Learning. Learning Communities Journal, 1(2), 7-10.

Belenky, M.F., Clinchy, B.M., Goldberger, N.R., \& Tarule, J.M. (1986). Women's Way of Knowing: The Development of Self, Voice, and Mind. New York: Basic Books.

Cox, M.D. (2018). Learning Community Structures, Venues, Pathways, and Outcomes-From Traditional to Extreme. Learning Communities Journal, 10(1), 23-29.

Ethington, C., \& Smart, J.C. (1986). Persistence to Graduate Education. Research in Higher Education, 24, 287-303.

Finley, N. (1991). What Differences do Learning Communities Make with Faculty? An Inside View: Conversations about Curriculum Reform at Seattle Central. Washington Center News, 6(1). Olympia, Washington: Washington Center for Undergraduate Education. The Evergreen College.

Gabelnick, F.J., MacGregor, J., Matthews, R.S., \& Smith, B.L. (1990). Learning Communities: Creating Connections among Students, Faculty, and Disciplines. San Francisco: Josey-Bass, Incorporated Publishers.

Graff, M. (2003). Individual Differences in Sense of Classroom Community in a Blended Learning Environment. Journal of Educational Media, 28(2-3), 203-210.

Hatcher, J.A., Shaker, G.G., \& Freeman, T.M. (2016). Faculty Learning Communities: Taking Collective Action to Improve Teaching and Learning in Nonprofit and Philanthropic Studies. Journal of Nonprofit Education and Leadership, 6(3), 254-272. 
Henscheid, J.M. (2015). It is Time to Count Learning Communities. Learning Communities Research and Practices, 3(2), 9-12.

Hubbard, H., Clark, A., \& Beech, A.L. (2004). Assessing Faculty Learning Communities. Special Issue: Building Faculty Learning Communities, 2004(97), 87-100.

Matthews, R. (1994). Enriching Teaching and Learning through Learning Communities. Teaching and Learning in the Community College. Washington, D.C. American Association of Community Colleges.

Pace, C.R. (1974). The Demise of Diversity? A Comparative Profile of Eight Types of Institutions. Berkeley, California: The Carnegie Commission on Higher Education.

Pace, C.R. (1984). Measuring the Quality of College Student Experiences. Los Angeles: University of California, Higher Education Research Institute.

Pascarella, E.T. (1984). College Environmental Influences on Students' Educational Aspirations. Journal of Higher Education, 55, 751-771.

Peterson, M.W., \& White, T.H. (1992). Faculty and Administrators' Perceptions of Their Environments: Different Views or Different Models of Organizations? Research in Higher Education, 33(2), 177-204.

Schussler, D., \& Fierros, E. (2008). Students' Perceptions of Their Academics, Relationships, and Sense of Belonging: Comparisons Across Residential Learning Communities. Journal of the First Year Experience \& Students in Transition, 1, 71-96.

Skagit Valley College. (1992). Learning Communities: A Study of Types of Learning, Retention, and Perceptions of Students and Faculty in Linked and Coordinated Courses at Skagit Valley College. Reports prepared for Skagit Valley College Assessment Steering Committee. Skagit Valley, Washington: Skagit Valley College.

Smart, J.C. (1986). College Effects on Occupational Status Attainment. Research in Higher Education, $24,73-95$.

Smith, B.L. (1988). Learning Communities: A Paradigm for Educational Revitalization. Community College Review, 15(4), 1-7.

Smith, B.L. (1991). Taking Structure Seriously: The Learning Community Model. Liberal Education, 77, $42-48$.

Stoecker, J., \& Pascarella, E.T. (1988). Institutional Gender and the Early Educational, Occupational, and Economic Attainments of Women. Proceedings, American Educational Research Association. New Orleans, La.

Stoecker, J., Pascarella, E.T., \& Wolfle, L. (1988). Persistence in Higher Education: A Nine-Year Test of a Theoretical Model. Journal of College Student Development, 29, 196-209.

Tollefson, G. (1990). Collaborative Learning Communities in Washington Community Colleges. Ph.D. dissertation, Seattle University.

Wicks, D.A., Craft, B.B., Mason, G.N., Gritter, K., \& Bolding, K. (2015). An Investigation into the Community of Inquiry of Blended Classrooms by a Faculty Learning Community. The Internet and Higher Education, 25, 53-62. 